\title{
Ciências da Comunicação: teorias e metodologias tentativas
}

Neste terceiro número de 2012, a E-Compós publica o dossiê temático Teorias e Metodologias da Comunicação. Com a dinâmica peculiar ao campo da comunicação e suas interfaces com indústria, tecnologia, política, cultura e mercado, teorias e métodos de pesquisa precisam ser continuamente repensados para lidar com fenômenos e questões emergentes. Com esta edição, nossa intenção foi colaborar com a fomentação e atualização dos debates sobre estes temas.

0 texto de José Luiz Braga, Uma teoria tentativa, busca teorizar a noção de 'dispositivo interacional', a partir da pesquisa empírica que 0 autor conduz sobre 0 tema. Em A Velha Europa e o Sociólogo, Hans Ulrich Gumbrecht revisita a obra de Niklas Luhmann e sua contribuição para 0 pensamento ocidental. 0 texto, inédito em português e inglês, foi publicado originalmente em alemão, e traduzido especialmente para esta edição.

0 artigo de Rodrigo Travitzki, Marco Toledo Bastos e Rafael Luís Galdini Raimundo, 0 perspectivismo como fundamento para metodologias de análise das redes sociais: alguns resultados com o Twitter apresenta uma abordagem perspectivista para lidar com os numerosos dados disponíveis nos logfiles de redes sociais como 0 Twitter. 
No texto Pela adoção da perspectiva da pertinência em

pesquisas comunicacionais, de Carlos Alberto de Carvalho e

Leandro Lage, é proposta uma articulação de fundamentação hermenêutica entre teoria, empiria e análise para as pesquisas em comunicação.

A discussão teórica sobre o som e 0 silêncio, a vida e a morte na narrativa cinematográfica é o tema de fundo do artigo Cinema in extremis: notas sobre um silêncio estridente em 0 homem urso, de Marcelo Carvalho da Silva.

Na seção de resenhas, Leonel Aguiar comenta 0 lançamento em português do clássico $O$ Viés da Comunicação, livro de Harold Innis lançado originalmente em 1951 com o título The Bias of Communication e só agora lançado no Brasil.

Finalmente, na seção de entrevistas, temos a honra de apresentar uma entrevista com Christine Hine, pesquisadora inglesa da University of Surrey e referência mundial em metodologias de pesquisa etnográfica em ambientes digitais, concedida a Adriana Braga, no texto Etnografia segundo Christine Hine: abordagem naturalista para ambientes digitais.

Nossos votos de um excelente 2013 e desejamos uma boa leitura!

Comissão Editorial 